\title{
Morphological and Morphometrical Studies on the Skull of Binturong (Arctictis binturong)
}

\author{
Pranab Chandra Kalita, Swarup Debroy, Om Prakash Choudhary", Arup Kalita and Probal Jyoti Doley \\ Department of Veterinary Anatomy and Histology, College of Veterinary Sciences and Animal Husbandry, Central Agricultural \\ University, Selesih, Aizawl, Mizoram, INDIA \\ "Corresponding author: OP Choudhary; E-mail:dr.om.choudhary@gmail.com
}

Received: 27 Feb., $2020 \quad$ Revised: 12 March, $2020 \quad$ Accepted: 19 March, 2020

\begin{abstract}
The binturong or bearcat is the largest species of the family Viverridae. It is uncommon in much of its range and has been assessed as vulnerable on the IUCN red list. The size of the head was small, narrow and light in proportion to the body. The skull of the binturong was dolichocephalic as per the cephalic index (56.25). There was no prominent internasal suture and the orbits were incomplete with optic foramen present near the ventral surface. The mean skull length, skull width, skull base length, cranial length, cranial width, cranial height, were $14.95 \pm 0.10 \mathrm{~cm}, 8.47 \pm 0.10 \mathrm{~cm}, 15.07 \pm 0.02 \mathrm{~cm}, 11.16 \pm 0.09 \mathrm{~cm}, 6.56 \pm 0.11 \mathrm{~cm}$, $3.16 \pm 0.08 \mathrm{~cm}$, respectively. The mean facial length, facial width, maxilla length, maxilla height, distance between infraorbital foramen, diameter of infraorbital foramina, nasal length, nasal width were $4.95 \pm 0.08 \mathrm{~cm}, 6.14 \pm 0.12 \mathrm{~cm}, 4.46 \pm 0.01 \mathrm{~cm}, 3.83 \pm 0.02$ $\mathrm{cm}, 4.68 \pm 0.10 \mathrm{~cm}, 0.49 \pm 0.07 \mathrm{~cm}, 2.94 \pm 0.03 \mathrm{~cm}, 1.97 \pm 0.11 \mathrm{~cm}$, respectively. Scanty literature available on morphological and morphometrical studies of the skull of binturong. Therefore this present study was aimed to establish a morphometric database that will eventually guide the use of these measurements for diagnosis and treating different disorders.
\end{abstract}

Keywords: Binturong, skull, morphological, morphometrical, cephalic index, IUCN red list

The binturong (Arctictis binturong) or bearcat is the largest species of the family Viverridae, classified in the order of Carnivora. It is an arboreal and primarily nocturnal omnivore measuring up to 1.5 meters in length including the long, prehensile tail and has a natural range from southeast Asia and Malaysia to the Philippines (Bjornson et al., 1999). It generally uses the upper part of the canopy (about 20 meters high) to find its food, the middle part (between 10 and 20 meters high) to rest and rarely goes on the ground, seemingly due to the presence of its predators (Grassman et al., 2005). With its thick covering of long dark hair, the binturong is a distinctive animal, although held in relatively few zoological collections (Bjornson et al., 1999). In addition, present to exhibiting rare physiologic particularities, this species plays a significant role within its ecosystem. Rather unknown to the general public, a lack of scientific knowledge persists on the bearcat's ecology and ethology (Widmann et al., 2008). It is uncommon in much of its range and has been assessed as vulnerable on the IUCN red list because of a declining population trend that is estimated at more than $30 \%$ since the mid-1980s (Willcox et al., 2016).

Although gross anatomical studies on the different body parts of the binturong have been published in the literature earlier; however, the studies related to the morphological and morphometrical studies on the skull of binturong is almost none. Therefore, the present study was designed to establish morphological and morphometrical database on the skull of the binturong, which will eventually guide the use of these measurements for diagnosis and treating different disorders on the head region.

How to cite this article: Kalita, P.C., Debroy, S., Choudhary, O.P., Kalita, A. and Doley, P.J. (2020). Morphological and morphometrical studies on the skull of binturong (Arctictis binturong). J. Anim. Res., 10(2): 309-314. 


\section{MATERIALS AND METHODS}

The present study was performed on the skull of the binturong. The samples were collected from the Aizawl Zoological Park, Government of Mizoram with permission from the Department of Environment, Forest and Climate change, Government of Mizoram. The collected samples were prepared using the boiling maceration technique for skeleton preparation (Simoens et al., 1994; Choudhary et al., 2015; Choudhary and Singh, 2015a, 2016). This particular study was performed to establish baseline data on the regional anatomy of the head covering its morphological and morphometric parameters. The following skull parameters were measured during the study and summarized in Figs. 1 to 4.

\section{Skull Parameters}

1. Skull Length (Lsk): Distance between the highest points of the parietal bone to the middle of the rostral margin of the incisive bone.

2. Skull Width (Wsk): Distance between two zygomatic arches.

3. Skull Base Length (LBsk): Distance between the midpoints of the dorsal margin of the foramen magnum to the level of the middle point of the rostral margin of the incisive bone.

4. Skull/Cephalic Index (SI): Skull width/skull height X 100 (Miller et al., 1964).

\section{Cranial Parameters}

1. Cranial length (Lcr): Distance from the central point of the frontonasal suture to the middle point of the nuchal crest.

2. Cranial width (Wcr): Maximum distance between the highest point of the parietal bones.

3. Cranial index (Icr): Cranial width/ cranial length $\mathrm{X}$ 100 (Miller et al., 1964).

4. Cranial height (Hcr): Distance between the central points of the ventral rim of the foramen magnum to the middle point of the nuchal crest.

5. Height of foramen magnum (Hfm): The distance between the midpoints of the dorsal-ventral rims of the foramen magnum.
6. Width of foramen magnum (Wfm): The maximum distance between the two occipital condyles.

7. Height of occipital (Hoc): Distance from base of the occipital condyle to the starting point of sagittal crest.

8. Width of occipital (Woc): Maximum distance between external margins of two paracondylar processes.

9. Circumference of foramen magnum (Cfm): Length of the entire rim of the foramen magnum.

\section{Facial Parameters}

1. Facial length (FL): Distance from the frontonasal suture to the centre of the incisive bone.

2. Facial width (FW): Distance between the caudal extents of the orbital rims.

\section{Frontal Parameters}

1. Length of frontal (Lfr): Maximum length between paritofrontal suture and frontonasal suture.

2. Width of frontal (Wfr): Maximum length between two lateral edges of the frontal bone.

3. Distance between supraorbital foramen (Dsof): Distance between two supraorbital foramen of the frontal bone.

\section{Orbital Parameters}

1. Orbital length (Ho): Maximum height of the orbit.

2. Orbital height (Lo): The perpendicular distance between the supraorbital and infraorbital margins of the orbit.

3. Orbital depth (Do): Distance between optic foramen and centre of the orbital rim.

\section{Maxilla Parameters}

1. Length of maxilla (Lma): Maximum length of the maxilla.

2. Height of maxilla (Hma): Maximum width of the maxilla.

3. Distance between infraorbital foramen (Diof): Maximum distance between two infraorbital foramen. 


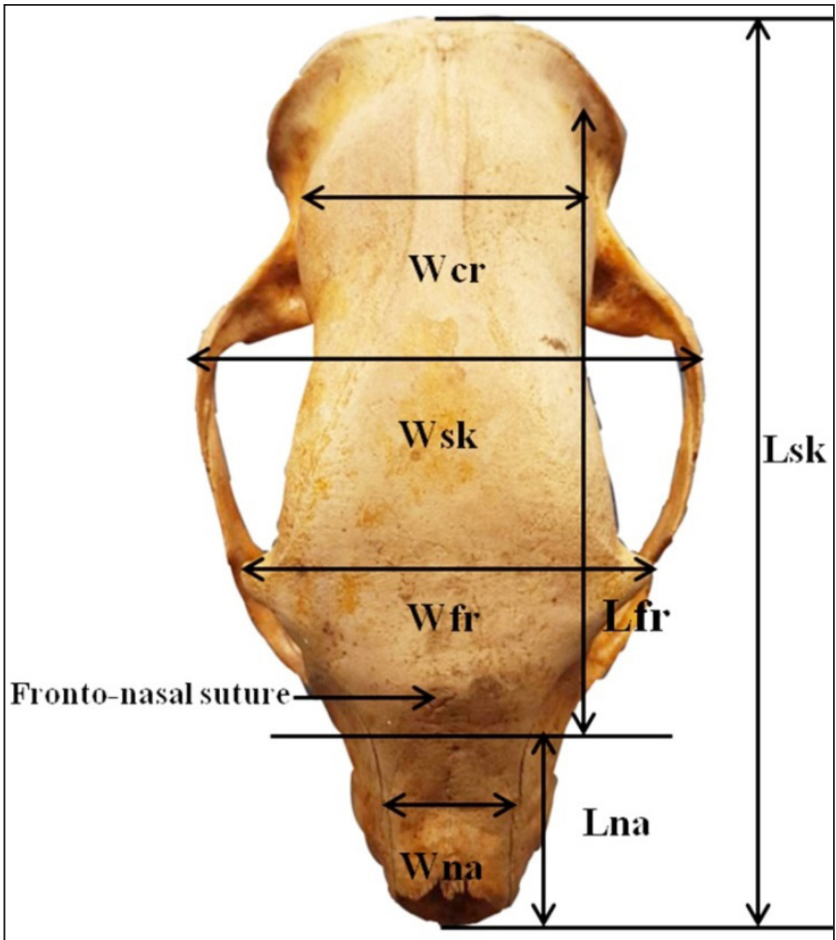

Fig. 1: Measurement of the skull of binturong (dorsal view) showing skull length (Lsk), skull width (Wsk), length of frontal (Lfr), width of frontal (Wfr), distance between supraorbital foramina to rim of orbit (Sof-rio) length of nasal (Lna) and width of nasal (Wna) and cranial width (Wcr)

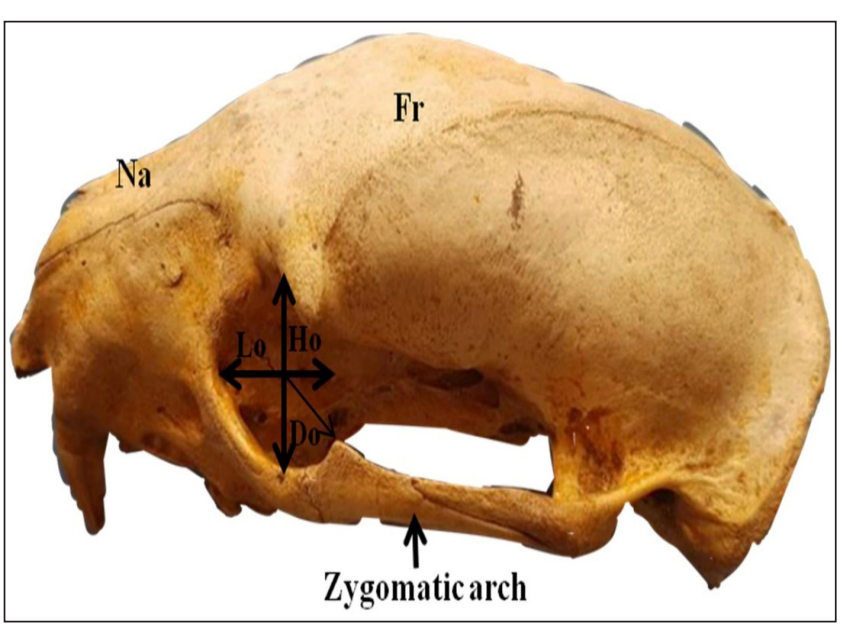

Fig. 3: Measurement of the skull of binturong (Lateral view) showing height of the orbit (Ho), length of the orbit (Lo), depth of orbit (Do), Frontal (Fr), Nasal (Na) and zygomatic arch

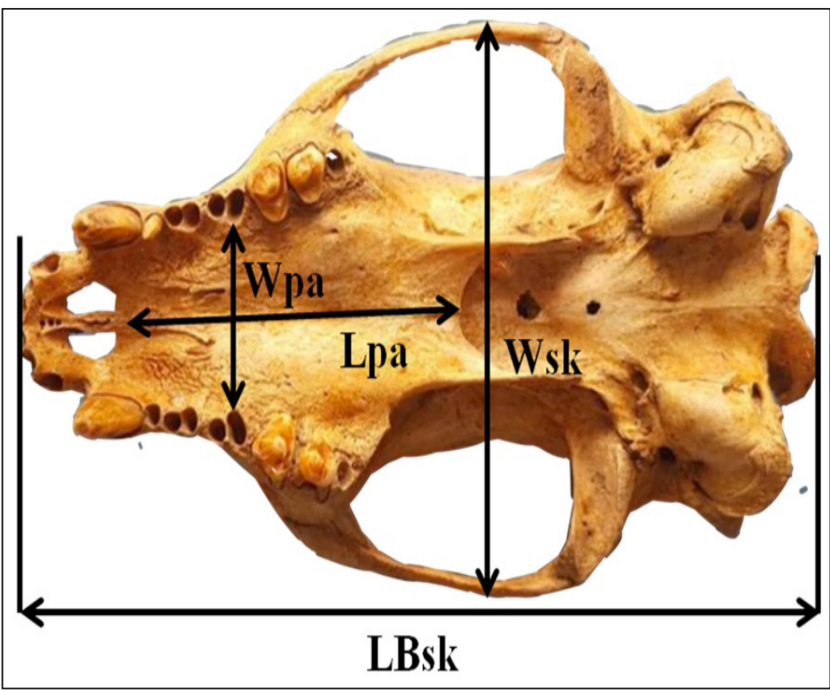

Fig. 2: Measurements of the skull of binturong (ventral view) showing the base length of the skull (LBsk), width of the skull (Wsk), length of the palatine (Lpa), width of the palatine (Wpa)

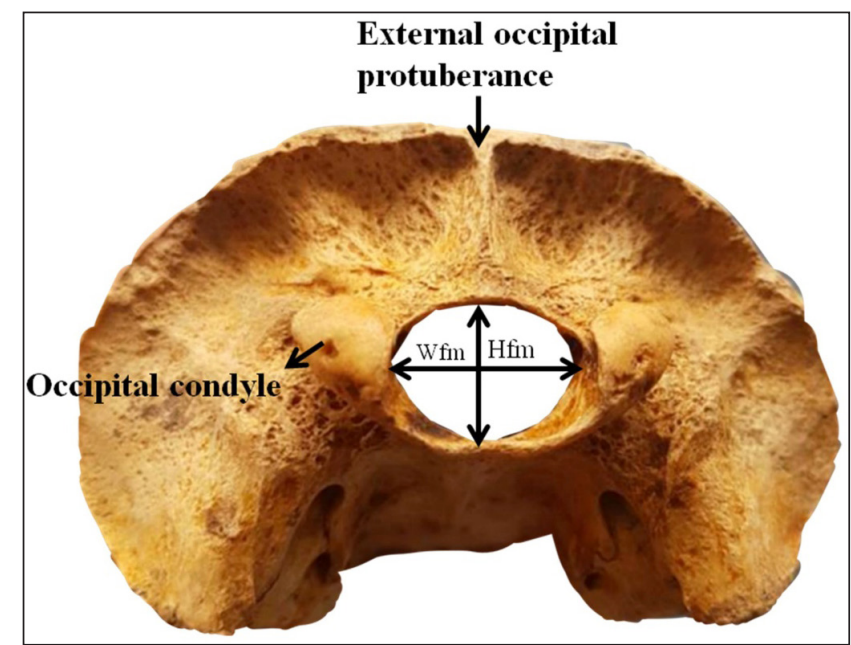

Fig. 4: Measurement of the skull of binturong (Caudal view) showing height of the foramen magnum $(\mathrm{Hfm})$, Width of the foramen magnum (Wfm) 
4. Diameter of infraorbital foramina (Diof): Maximum distance between the two edges of infraorbital foramina.

\section{Nasal Parameters}

1. Length of nasal bone (Lna): Distance from the central point of the frontonasal suture to the rostral end of the internasal suture.

2. Width across nasal bone (Wna): Maximum distance across the nasal bones or maximum distance between the naso-maxillary sutures.

3. Nasal Index (Ina)=Nasal width/ Nasal length X 100 .

\section{Palatine Parameters}

1. Length of palate (Lpa): Distance measured from the rostral mid sutured line of incisive bone to the caudal nasal spine of the palatine bone.

2. Width of palate (Wpa): Maximum distance at the horizontal plate of palatine bone behind the last molar tooth.

\section{Zygomatic Parameters}

1. Length of zygomatic (Lzy): Maximum length of Zygomatic.

2. Height of zygomatic (Hzy): Maximum height of Zygomatic.

These parameters of the skull were measured using digital Vernier caliper and subjected to routine statistical analysis Snedecor and Cochran (1994).

\section{RESULTS AND DISCUSSION}

\section{Morphological studies}

The size of the head of the binturong was small, narrow and light in proportion to the body, whereas the size of the head was small, narrow and light in Malayan sun bear (Kalita et al., 2019). The skull was elongated in shape as also mentioned in blackbuck (Choudhary and Singh, 2015b). The binturong skull was divided into frontal, lateral, nuchal and basal surfaces. The frontal surface of the skull was formed by the frontal, parietal, interparietal, nasal, small part of maxilla and premaxilla bones as reported in Pygmy hog (Kalita et al., 2015) and Zovawk pig (Choudhary et al., 2019a). The caudal extent of the frontal surface is formed by the parietal bone and the frontal eminence was present on the median line, at the middle of the frontals similar findings were found in Kagani goat (Sarma, 2006) where the frontal bone extended upto the caudal extent of the skull as reported in cattle (Getty, 1975), Mithun (Borthakur et al., 2000) and dum pig (Sarma et al., 2002). The nasal bones had a convex dorsal surface with a shallow depression in the middle of the nasal surface and terminated into a broad rostral end. There was no prominent internasal suture, whereas Nickel et al., 1981 observed a prominent straight internasal suture. The orbits were incomplete with optic foramen present near the ventral surface.as also reported in Pygmy hog (Kalita et al., 2015) and Indian wild pig (Choudhary et al., 2017). The basilar part of the occipital and sphenoid bone was straight as also reported in Kagani goat (Sarma, 2006) and Mizoram goats (Choudhary et al., 2019b). The external occipital protuberance was like a thin prominent crest.

The elongated paracondylar processes were attached to tympanic bulla on either side. The temporal fossa of binturong was deep but short, caudal to which two numbers of foramina were present on each side. The basilar part of the occipital and sphenoid bone was straight. The tympanic bullae were comparatively large and rounded. Median palatine suture, transverse palatine suture, major palatine foramen, minor palatine foramen were missing.

\section{Morphometrical studies}

The skull of the binturong was dolichocephalic according to the cephalic index (56.25) as reported in Zovawk pig (Choudhary et al., 2019a). However, the skull was mesocephalic in Malayan sun bear (Kalita et al., 2019). The mean skull length, skull width, skull base length, cranial length, cranial width, cranial height, were $14.95 \pm 0.10 \mathrm{~cm}$, $8.47 \pm 0.10 \mathrm{~cm}, 15.07 \pm 0.02 \mathrm{~cm}, 11.16 \pm 0.09 \mathrm{~cm}, 6.56 \pm 0.11$ $\mathrm{cm}, 3.16 \pm 0.08 \mathrm{~cm}$, respectively. Saber and Gummow (2015) reported that mean skull length, skull width, cranial length and cranial width of the cat was $8.4 \pm 1.50 \mathrm{~cm}$, $6.8 \pm 1.40 \mathrm{~cm}, 3.4 \pm 0.40 \mathrm{~cm}$, and $4.1 \pm 0.20 \mathrm{~cm}$, respectively. Choudhary et al. (2016) mentioned that the skull length, 
skull width and cranial length for the dromedary camels were $48.75 \pm 0.24 \mathrm{~cm}, 22.66 \pm 0.10 \mathrm{~cm}$ and $32.73 \pm 0.48$ $\mathrm{cm}$, respectively. Kalita et al. (2019) also reported that the skull length, skull width, cranial length, maximum skull height, skull breadth at parietals, skull height at the mastoid process, skull breadth at the junction of frontal and parietal (Waist) and height of rostrum at canine alveolus were $21.47 \mathrm{~cm}, 17.28 \mathrm{~cm}, 17.81 \mathrm{~cm}, 9.40 \mathrm{~cm}, 8.00 \mathrm{~cm}$, $8.30 \mathrm{~cm}, 7.00 \mathrm{~cm}$ and $4.10 \mathrm{~cm}$, respectively. The cranial index was 58.78 in binturong. However, the cranial index of the koala, wombat and wallaby was 48.78, 111.21 and 74.75, respectively (Saber and Gummow, 2015).

The mean height of foramen magnum, width of foramen magnum, circumference of foramen magnum, height of occipital, width of occipital was $1.19 \pm 0.17 \mathrm{~cm}$, $2.95 \pm 0.08 \mathrm{~cm}, 4.94 \pm 0.09 \mathrm{~cm}, 2.57 \pm 0.01 \mathrm{~cm}, 5.95 \pm 0.09$ $\mathrm{cm}$ respectively. The height and width of the occipital bone was found to be $10.89 \pm 0.01 \mathrm{~cm}$ and $7.97 \pm 0.01 \mathrm{~cm}$, respectively in Zovawk (Choudhary et al., 2019a). In contrast, the same occipital parameter was $5.21 \pm 0.01 \mathrm{~cm}$ and $5.76 \pm 0.008 \mathrm{~cm}$, respectively in blackbuck (Choudhary and Singh, 2015b). The foramen magnum height, width and circumference of Malayan sun bear were found to be $3.50 \mathrm{~cm}, 3.20 \mathrm{~cm}$ and $10.52 \mathrm{~cm}$, respectively (Kalita et al., 2019).

The length and width of the frontal bone of binturong was $10.41 \pm 0.01 \mathrm{~cm}$ and $5.73 \pm 0.01 \mathrm{~cm}$, respectively. The supraorbital foramina were single on either side, each lying at the dorsolateral aspect of a roughly quadrilateral depression. A distance between two supraorbital foramen was $58.05 \pm 1.2$. Whereas length and width of the frontal bone was $7.75 \pm 0.01 \mathrm{~cm}$ and $4.81 \pm 0.00 \mathrm{~cm}$, respectively in blackbuck (Choudhary and Singh, 2015b).

In the present study, the mean facial length, facial width was $4.95 \pm 0.08 \mathrm{~cm}$ and $6.14 \pm 0.12 \mathrm{~cm}$, respectively. Saber and Gummow (2015) found that the mean facial length of the lion's, dog's and cat's skulls were $17.88 \pm 5.59 \mathrm{~cm}$, $14.16 \pm 0.89 \mathrm{~cm}$ and $5.0 \pm 1.5 \mathrm{~cm}$, while the mean facial width was $17.75 \pm 5.19 \mathrm{~cm}, 5.37 \pm 0.35 \mathrm{~cm}$ and $5.9 \pm 1.2 \mathrm{~cm}$ respectively.

The orbital height, length and depth of both the orbit were the same, which was $3.24 \pm 0.09 \mathrm{~cm}, 2.76 \pm 0.11 \mathrm{~cm}$ and $1.33 \pm 0.11 \mathrm{~cm}$, respectively. However, the height of the right orbit was more than the left one in Kagani goats (Sarma, 2006).
The maxilla length, maxilla height, distance between infraorbital foramen, diameter of infraorbital foramina, nasal length, nasal width were $4.46 \pm 0.01 \mathrm{~cm}, 3.83 \pm 0.02$ $\mathrm{cm}, \quad 4.68 \pm 0.01 \mathrm{~cm}, 0.49 \pm 0.07 \mathrm{~cm}, 0.29 \pm 0.01 \mathrm{~cm}$, $1.97 \pm 0.01 \mathrm{~cm}$, respectively. Kalita et al. (2019) found that the nasal length, nasal perpendicular height, nasal horizontal-transverse width and nasal circumference were $3.59 \mathrm{~cm}, 3.50 \mathrm{~cm}, 3.20 \mathrm{~cm}$ and $10.52 \mathrm{~cm}$, respectively.

The length and width of the palatine bone was $4.67 \pm 0.06$ $\mathrm{cm}$ and $3.71 \pm 0.05 \mathrm{~cm}$ in the present study whereas the length and width of palatine bone was $6.04 \pm 0.04 \mathrm{~cm}$ and $3.23 \pm 0.02 \mathrm{~cm}$, respectively in blackbuck (Choudhary and Singh, 2015b). The length of the palatine suture in the present study was $1.40 \pm 0.02 \mathrm{~cm}$.

The length and height of the zygomatic bone of binturong was $4.03 \pm 0.09 \mathrm{~cm}$ and $1.13 \pm 0.10 \mathrm{~cm}$, respectively. However, the length and width of the zygomatic bone was $8.26 \pm 0.02 \mathrm{~cm}$ and $4.26 \pm 0.01 \mathrm{~cm}$, respectively in Zovawk (Choudhary et al., 2019a).

\section{CONCLUSION}

These morphometric databases provide the blueprint for further research on the field of morphological and applied anatomy. The morphological and morphometric information acquired from the skull region of binturong has enormous importance in diagnostic and treating different skull disorder and also aid during the regional anesthesia of various nerves around the head.

\section{ACKNOWLEDGMENTS}

The authors are thankful to the Department of Environment, Forest and Climate Change, Government of Mizoram, Aizawl \& the Director, Aizawl Zoological Park, Aizawl, Mizoram for providing all the necessary facilities to carry out the research work.

\section{CONFLICT OF INTEREST}

The authors declare that they have no conflicts of interest concerning this manuscript.

\section{REFERENCES}

Bjornson, A.R., Lewis, J.C.M. and Appleby, E.C. 1999. Mammary neoplasia in a binturong (Arctictis binturong). Vet. Rec., 144(15): 421-422. 
Borthakur, S., Sarma, K., and Bhattacharya, M. 2000. Anatomy of the skull of Mithun (Bos frontalis). Indian J. Vet. Anat., 12: $1-5$.

Choudhary, O.P. and Singh, I. 2015a. Applied anatomy of the maxillofacial and mandibular regions of the Indian blackbuck (Antilope cervicapra). J. Anim. Res., 5(3): 497-500.

Choudhary, O.P. and Singh, I. 2015b. Morphometrical studies on the skull of Indian blackbuck (Antilope cervicapra). Int. J. Morphol., 33(3): 868-76.

Choudhary, O.P. and Singh, I. 2016. Morphological and radiographic studies on the skull of Indian blackbuck (Antilope cervicapra). Int. J. Morphol., 34(2): 788-796.

Choudhary, O.P., Kalita, P.C., Kalita, A. and Doley, P.J. 2017. Applied anatomy of the head region of the Indian wild pig (Sus scrofa) and its clinical value during regional anesthesia. J. Anim. Res., 7(2): 339-44.

Choudhary, O.P., Kalita, P.C., Kalita, A. and Doley, P.J. 2016. Applied anatomy of the maxillofacial and mandibular regions of the dromedary camel (Camelus dromedarius). J. Camel Pract. Res., 23(1): 127-131.

Choudhary, O.P., Kalita, P.C., Kalita, A., Doley, P.J. and Arya, R.S. 2019b. Morphological studies on the cranial bones of Mizoram goats. Indian J. Small Rumin., 25(1): 128-130.

Choudhary, O.P., Kalita, P.C., Konwar, B., Doley, P.J., Kalita, G. and Kalita, A. 2019a. Morphological and applied anatomical studies on the head region of local Mizo pig (Zovawk) of Mizoram. Int. J. Morphol., 37(1):196-204.

Choudhary, O.P., Singh, I., Bharti, S.K., Khan, I.M., Sathapathy, S. and Mrigesh, M. 2015. Gross and morphometrical studies on mandible of blackbuck (Antelope cervicapra). Int. J. Morphol., 33(2): 428-432.

Getty, R., Getty, R., Sisson, S. and Grossman, J.D. 1975. Sisson and Grossman's, the Anatomy of the domestic animals. Vol. I, $5^{\text {th }}$ edn. W.B. Saunders Company, Philadelphia, USA.

Grassman, L.I., Tewes, M.E., and Silvy, N.J. 2005. Ranging, habitat use and activity patterns of binturong Arctictis binturong and yellow-throated marten Martes flavigula in north-central Thailand. Wildlife Biol., 11(1): 49-57.

Kalita, P.C., Deka, A., Kalita, A., Doley, P.J. and Das, B.J. 2015. Morphology of the skull of pygmy hog (Porcula salvanias): A Forensic Approach. IOSR J. Agric. Vet. Sci., 8(1): 23-26.
Kalita, P.C., Singh, T.S., Choudhary, O.P., Debroy, S., Kalita, A. and Doley, P.J. 2019. Morphological and applied anatomical studies on the head region of Malayan sun bear (Helarctos malayanus). J. Anim. Res., 9(5): 753-758.

Miller, M.S., Christensen, G.C. and Evans, H.E. 1964. The skeletal system, skull. In Anatomy of dog. W.B. Saunders Co., Philadelphia, USA.

Monfared, A.L. 2013. Applied anatomy of the head regions of the one humped camel and its clinical implications during regional anesthesia. Global Vet., 10: 322-326.

Nickel, R., Schummer, A. and Seiferli, E. 1981. Anatomy of the domestic animals. Verlog Paul Parey, Berlin, Germany.

Olopade, J.O. and Onwuka, S.K. 2003. A preliminary investigation into some aspects of the craniofacial indices of the red sokoto (Maradi) goat in Nigeria. Folia Vet., 47(2): 57-59.

Saber, A.S.M. and Gummow, B. 2015. Skull morphometry of the lion (Panthera leo), dog (Canis lupus familiaris) and cat (Felis catus). J. Vet. Anat., 8(1): 13-30.

Sarma, K. 2006. Morphological and craniometrical studies on the skull of Kagani goat (Capra hircus) of Jammu region. Int. J. Morphol., 24(3): 449-455.

Sarma, K. and Sarma, M. 2002. Anatomy of the skull of dum pig of Assam. Indian Vet. J., 79(7): 708-711.

Simoens, P., Poels, P. and Lauwers, H. 1994. Morphometric analysis of the foramen magnum in Pekingese dogs. Amer. $J$. Vet. Res., 55(1): 34-39.

Snedecor, G.W. and Cochran, W.G. 1994. Statistical methods. $8^{\text {th }}$ edn. Iowa State University Press, Ames, Iowa, USA.

Widmann, P., De Leon, J., Duckworth, J.W. 2008. Arctictis binturong. In: IUCN red list threat. Species [en ligne]. [http://www.iucnredlist.org/details/41690/0] (Consultation le 29/11/15), accessed on $26^{\text {th }}$ February 2020.

Willcox, D.H.A., Chutipong, W., Gray, T.N.E., Cheyne, S., Semiadi, G., Rahman, H., Coudrat, C.N.Z., Jennings, A., Ghimirey, Y., Ross, J., Fredriksson, G. and Tilker, A. 2016. Arctictis binturong. The IUCN red list of threatened species 2016: e.T41690A45217088. 